\title{
Lung volume recruitment acutely increases respiratory system compliance in individuals with severe respiratory
} muscle weakness

\author{
Yannick Molgat-Seon ${ }^{1}$, Liam M. Hannan ${ }^{2,3}$, Paolo B. Dominelli ${ }^{1}$, \\ Carli M. Peters ${ }^{1}$, Renee J. Fougere ${ }^{4,5}$, Douglas A. McKim ${ }^{6,7}$, A. William Sheel ${ }^{1}$ \\ and Jeremy D. Road ${ }^{5,8}$
}

Affiliations: 'School of Kinesiology, University of British Columbia, Vancouver, Canada. ${ }^{2}$ Institute for Breathing and Sleep, Austin Hospital, Heidelberg, Australia. ${ }^{3}$ Faculty of Medicine, Dentistry and Health Science, University of Melbourne, Melbourne, Australia. ${ }^{4}$ Faculty of Nursing, University of Toronto, Toronto, Canada. ${ }^{5}$ Faculty of Medicine, University of British Columbia, Vancouver, Canada. ${ }^{6}$ Division of Respiratory Medicine, The Ottawa Hospital, Ottawa, Canada. ${ }^{7}$ Ottawa Hospital Research Institute, Ottawa, Canada. ${ }^{8}$ Division of Respiratory Medicine, Vancouver General Hospital, Vancouver, Canada.

Correspondence: Jeremy D. Road, Division of Respiratory Medicine, Vancouver General Hospital, 7th Floor, 2775 Laurel Street, Vancouver, British Columbia, V5Z 1M9, Canada. E-mail: jeremy.roaddavch.ca

ABSTRACT The aim of the present study was to determine whether lung volume recruitment (LVR) acutely increases respiratory system compliance $(\mathrm{Crs})$ in individuals with severe respiratory muscle weakness (RMW).

Individuals with RMW resulting from neuromuscular disease or quadriplegia $(n=12)$ and healthy controls $(n=12)$ underwent pulmonary function testing and the measurement of $C r s$ at baseline, immediately after, $1 \mathrm{~h}$ after and $2 \mathrm{~h}$ after a single standardised session of LVR. The LVR session involved 10 consecutive supramaximal lung inflations with a manual resuscitation bag to the highest tolerable mouth pressure or a maximum of $50 \mathrm{cmH}_{2} \mathrm{O}$. Each LVR inflation was followed by brief breath-hold and a maximal expiration to residual volume.

At baseline, individuals with RMW had lower $C$ rs than controls $\left(37 \pm 5 \mathrm{cmH}_{2} \mathrm{O}\right.$ versus $\left.109 \pm 10 \mathrm{~mL} \cdot \mathrm{cmH}_{2} \mathrm{O}^{-1}, \mathrm{p}<0.001\right)$. Immediately after LVR, Crs increased by $39.5 \pm 9.8 \%$ to $50 \pm 7 \mathrm{~mL} \cdot \mathrm{cmH}_{2} \mathrm{O}^{-1}$ in individuals with RMW $(\mathrm{p}<0.05)$, while no significant change occurred in controls $(\mathrm{p}=0.23)$. At $1 \mathrm{~h}$ and $2 \mathrm{~h}$ post-treatment, there were no within-group differences in Crs compared to baseline (all $\mathrm{p}>0.05$ ). LVR had no significant effect on measures of pulmonary function at any time point in either group (all $\mathrm{p}>0.05$ ). During inflations, mean arterial pressure decreased significantly relative to baseline by $10.4 \pm 2.8 \mathrm{mmHg}$ and $17.3 \pm 3.0 \mathrm{mmHg}$ in individuals with RMW and controls, respectively (both p<0.05).

LVR acutely increases $C r$ in individuals with RMW. However, the high airway pressures during inflations cause reductions in mean arterial pressure that should be considered when applying this technique.

@ERSpublications

Acute changes following lung volume recruitment http://ow.ly/2dqE308g3oG

Cite this article as: Molgat-Seon Y, Hannan LM, Dominelli PB, et al. Lung volume recruitment acutely increases respiratory system compliance in individuals with severe respiratory muscle weakness. ERJ Open Res 2017; 3: 00135-2016 [https://doi.org/10.1183/23120541.00135-2016].

This article has supplementary material available from openres.ersjournals.com

Received: Nov 252016 | Accepted after revision: Dec 232016

Support statement: Y. Molgat-Seon, P.B. Dominelli and C.M. Peters were supported by postgraduate scholarships from the Natural Sciences and Engineering Research Council (Canada). L.M. Hannan was supported by a postgraduate scholarship from the National Health and Medical Research Council (Australia).

Copyright $\odot$ ERS 2017. This article is open access and distributed under the terms of the Creative Commons Attribution Non-Commercial Licence 4.0. 


\section{Introduction}

Individuals with neuromuscular disorders or quadriplegia frequently have respiratory muscle weakness (RMW) resulting in restrictive ventilatory impairment and altered respiratory mechanics [1-3]. The inability to maximally inflate or deflate the lungs due to RMW truncates inspiratory and/or expiratory reserve volumes, thereby decreasing vital capacity (VC) and total lung capacity (TLC) $[4,5]$. The prolonged inability to fully inflate or deflate the lungs can decrease lung compliance due to either increased alveolar surface tension or decreased lung tissue elasticity [2,6]. Furthermore, chronically limiting the range of motion of the chest wall can decrease chest wall compliance by stiffening the tissues and joints of the rib cage $[3,7,8]$. In addition, the presence of RMW limits the ability to generate expired flow, which may decrease peak cough flow (PCF) below values necessary for effective airway clearance, thereby increasing the risk of respiratory tract infections [9-12]. The majority of morbidity and mortality in patients with neuromuscular disorders or quadriplegia is caused by respiratory complications resulting from chronic RMW $[12,13]$. Prevention of respiratory complications is thought to be largely dependent on mitigating the progressive decrease in lung volumes where possible, and maintaining effective cough $[11,14]$.

Lung volume recruitment (LVR) is used as a supportive therapy for individuals with RMW to passively increase lung volume, augment cough effectiveness and decrease the risk of respiratory complications [12, 15-17]. By applying positive inspiratory mouth pressure, LVR inflates the lungs to a volume higher than is achievable during spontaneous breathing. At higher lung volumes the static recoil pressure of the lung is increased, which increases maximal expired flow [18]. Studies have suggested that LVR improves PCF by assisting expiration immediately following inflation [19], and increasing unassisted PCF thereafter [20]. Furthermore, studies have suggested that LVR could attenuate the decline in pulmonary function in Duchenne muscular dystrophy by increasing or maintaining compliance of the lung and chest wall, and thus reducing the work of breathing $[15,16]$. However, attempts to identify an acute effect from passive lung inflation in individuals with RMW have not demonstrated changes in either lung or total respiratory compliance $\left(C_{r s}\right)[21,22]$, but these studies did not perform manual inflations and used relatively low inflation pressures [21, 22]. Accordingly, our objective was to determine whether LVR acutely increases Crs in individuals with RMW. We hypothesised that Crs would be increased immediately following LVR before returning to baseline levels within $2 \mathrm{~h}$.

\section{Methods}

Subjects

12 individuals (males $\mathrm{n}=11$ ) with severe RMW requiring nocturnal noninvasive positive pressure ventilation due to neuromuscular disorders (Duchenne muscular dystrophy $n=8$, Becker muscular dystrophy $\mathrm{n}=1$ and type II spinal muscular atrophy $\mathrm{n}=1$ ) or spinal cord injury (chronic C5 injury $\mathrm{n}=2$ ) participated. Those with respiratory disease, a tracheostomy or requiring daytime assisted ventilation were excluded. Subjects in the RMW group were compared to 12 sex-matched healthy nonsmoking controls with no history of cardiovascular or respiratory disease. Informed consent was obtained, and all procedures were approved by the University of British Columbia's clinical research ethics board.

\section{Experimental overview}

Subjects underwent baseline pulmonary function testing including measurements of maximal inspiratory (MIP) and expiratory pressures (MEP), spirometry, peak expiratory flow (PEF), PCF, lung volumes and Crs. Subjects then underwent a standardised session of LVR. Measurements of PEF, PCF, lung volumes and Crs were repeated immediately following LVR $(0 \mathrm{~h}), 1 \mathrm{~h}$ after LVR $(1 \mathrm{~h})$ and $2 \mathrm{~h}$ after LVR $(2 \mathrm{~h})$.

\section{Pulmonary function testing}

MIP and MEP were assessed at residual volume (RV) and TLC, respectively. Spirometry, measurements of PEF and PCF were performed using a portable spirometer (Spirolab-II; Medical International Research, Vancouver, Canada). Lung volumes were assessed using the helium dilution technique (HypAir; Medisoft, Sorinnes, Belgium). The inert gas dilution method of assessing static lung volumes was used in order to ensure that the only the communicating fraction of lung volume was measured. Pulmonary function tests were performed according to standard recommendations [23-25] and expressed in absolute terms and as a percentage of predicted normal values [26-28].

\section{Respiratory system compliance}

During measurement of $\mathrm{Crs}$, subjects wore a nose clip and breathed through a circuit attached to a two-way pneumatic valve with one end open to the atmosphere, and the other connected to a tank of compressed air. While breathing on the circuit, flow rate, volume and mouth pressure $(P$ mo $)$ were measured continuously. Measurements of $C$ rs were made using the pulse method [29], which involves the delivery of a pulse of air at a constant flow rate of $\sim 0.3 \mathrm{~L} \cdot \mathrm{s}^{-1}$ over $2 \mathrm{~s}$ from end-expiratory lung volume. During each pulse, subjects were relaxed while air passively inflated their lungs, thereby causing a 
progressive increase in $P$ mo that is inversely proportional to Crs. Multiple measurements were made at each time point until at least five acceptable measures were obtained. A more detailed description of $\mathrm{Crs}$ measurement is provided in the online supplementary material.

\section{Lung volume recruitment}

During LVR, subjects breathed on the same circuit used during the Crs measurements but with a manual resuscitation bag attached to the pneumatic valve instead of the tank of compressed air. Following a maximal inspiration, the pneumatic valve position was switched and positive pressure was applied manually by performing compressions of the resuscitation bag over $\sim 2 \mathrm{~s}$ (defined as the inflation phase) to the highest tolerable $P$ mo $\leqslant 50 \mathrm{cmH}_{2} \mathrm{O}$. After a $\sim 6 \mathrm{~s}$ breath-hold at peak $P$ mo (defined as the plateau phase), subjects forcefully exhaled to RV and PEF (PEFLVR) was measured. Maximal insufflation capacity (MIC) was defined as the volume expired following each LVR manoeuvre, as previously described [19]. Thus, the difference between VC and MIC provided a measure of "recruitment volume" for each LVR manoeuvre. Each subject performed 10 consecutive LVR manoeuvres. Dyspnoea was assessed at baseline, $0 \mathrm{~h}, 1 \mathrm{~h}$ and $2 \mathrm{~h}$ using the modified $0-10$ Borg scale [30].

\section{Blood pressure and heart rate}

Measures of mean arterial pressure $(P \mathrm{a})$ and heart rate were obtained continuously during LVR using finger pulse photoplethysmography (Finometer; FMS, Arnhem, the Netherlands). Additional information regarding the measurement of mean $P$ a and heart rate is provided in the online supplementary material.

\section{Data processing}

All data were recorded continuously at $200 \mathrm{~Hz}$ using a four-channel analogue-to-digital data acquisition system (PowerLab-4/35 and LabChart v8.0; ADInstruments, Colorado Springs, CO, USA).

\section{Statistical analysis}

Descriptive characteristics and baseline pulmonary function parameters were compared between groups using independent t-tests. The association between $\mathrm{VC}$ and $\mathrm{Crs}$ was assessed using linear regression analysis. Lung volumes, Crs, PEF, PEFLVR, PCF and dyspnoea were compared using a two-way repeated measures analysis of variance on ranks. If significant F-ratios were detected, Tukey's post hoc test was applied. Significance was set at $\mathrm{p}<0.05$. All values are presented as mean \pm SEM unless otherwise noted. All analyses were performed using a statistical software package (SPPS v20.0; IBM, Armonk, NY, USA).

\section{Results}

Subjects

Subject characteristics are shown in table 1. The RMW and control groups were similar in terms of age, height and weight (all p>0.05). The RMW group had significantly lower MIP and MEP than controls (both $\mathrm{p}<0.001$ ). At baseline, the RMW group had significantly lower forced vital capacity and forced expiratory volume in $1 \mathrm{~s}$ than controls (both $\mathrm{p}<0.001$ ).

\section{Lung volume recruitment}

Data from LVR are presented in table 2. There were no significant between-group differences in inflation time $(\mathrm{p}=0.45)$ or plateau time $(\mathrm{p}=0.37)$. Controls reached a significantly higher peak $P$ mo than subjects in the RMW group $\left(38.9 \pm 1.7 \mathrm{cmH}_{2} \mathrm{O}\right.$ versus $\left.31.9 \pm 2.5 \mathrm{cmH}_{2} \mathrm{O}, \mathrm{p}<0.05\right)$. Inflations significantly increased lung volume above VC in the RMW group $(p<0.05)$, but not in the control group $(p=0.55)$. Accordingly, the difference between MIC and VC was significantly greater in the RMW group than the control group $(\mathrm{p}<0.05)$. The LVR manoeuvres were generally well tolerated, and there were no significant changes in dyspnoea relative to baseline at $0 \mathrm{~h}, 1 \mathrm{~h}$ and $2 \mathrm{~h}$ (all $\mathrm{p}>0.05$ ).

\section{Respiratory system compliance}

At baseline, Crs was significantly lower in individuals with RMW relative to controls $(\mathrm{p}<0.001)$ (table 1 , figure 1). The decreased Crs in the RMW group was significantly related to the degree of impairment in VC $(r=0.65, p<0.05)$. In the RMW group, LVR induced a $39.5 \pm 9.8 \%$ increase in Crs relative to baseline at $0 \mathrm{~h}(\mathrm{p}<0.05)$, however, no significant differences were observed at $1 \mathrm{~h}(\mathrm{p}=0.11)$ and $2 \mathrm{~h}(\mathrm{p}=0.26)$. LVR had no significant effect on $C r$ in the control group at $0 \mathrm{~h}, 1 \mathrm{~h}$ or $2 \mathrm{~h}$ following LVR (all $\mathrm{p}>0.05$ ).

\section{Lung volumes}

Subjects in the RMW group showed evidence of restrictive ventilatory impairment with a significantly lower baseline TLC, inspiratory capacity, functional residual capacity, and expiratory reserve volume (all $\mathrm{p}<0.05$ ), but similar RV relative to controls $(\mathrm{p}=0.92)$ (table 1$)$. LVR had no significant effect on lung volumes in either group at any time point following LVR (all p>0.05) (table 3). 


\section{TABLE 1 Subject characteristics}

\begin{tabular}{|c|c|c|c|c|}
\hline & RMW & Controls & p-value ${ }^{\#}$ & p-value \\
\hline Age years & $29 \pm 3$ & $29 \pm 2$ & 0.68 & \\
\hline Sex male: female & $11: 1$ & $11: 1$ & & \\
\hline Height cm & $163 \pm 6$ & $174 \pm 2$ & 0.17 & \\
\hline Weight kg & $59.5 \pm 8.2$ & $71.4 \pm 1.9$ & 0.26 & \\
\hline FVC L (\% pred) & $1.14 \pm 0.24(23.9 \pm 4.1)$ & $5.10 \pm 0.21(99.5 \pm 3.0)$ & $<10^{-11}$ & $<10^{-12}$ \\
\hline FEV 1 (\% pred) & $1.03 \pm 0.19(27.8 \pm 4.6)$ & $4.10 \pm 0.18(102.4 \pm 4.8)$ & $<10^{-10}$ & $<10^{-9}$ \\
\hline TLC L (\% pred) & $2.72 \pm 0.48(44.6 \pm 5.9)$ & $6.77 \pm 0.24(97.1 \pm 2.4)$ & $<10^{-7}$ & $<10^{-7}$ \\
\hline VC L (\% pred) & $1.17 \pm 0.23(24.03 \pm 4.0)$ & $5.24 \pm 0.18(102.8 \pm 3.5)$ & $<10^{-11}$ & $<10^{-11}$ \\
\hline IC L (\% pred) & $0.96 \pm 0.21(29.1 \pm 4.8)$ & $3.43 \pm 0.17(95.9 \pm 4.9)$ & $<10^{-8}$ & $<10^{-8}$ \\
\hline FRC L (\% pred) & $1.77 \pm 0.29(62.2 \pm 7.8)$ & $3.30 \pm 0.19(97.3 \pm 4.3)$ & $<10^{-11}$ & $<10^{-3}$ \\
\hline ERV L (\% pred) & $0.22 \pm 0.06(12.5 \pm 2.6)$ & $1.78 \pm 0.10(103.2 \pm 5.6)$ & $<10^{-11}$ & $<10^{-10}$ \\
\hline RV L (\% pred) & $1.55 \pm 0.27(118.1 \pm 16.4)$ & $1.52 \pm 0.12(91.5 \pm 5.1)$ & 0.92 & 0.32 \\
\hline MIP $\mathrm{cmH}_{2} \mathrm{O}(\%$ pred $)$ & $29.6 \pm 6.02(28.5 \pm 7.7)$ & $132.89 \pm 7.17(126.3 \pm 6.7)$ & $<10^{-9}$ & $<10^{-8}$ \\
\hline MEP $\mathrm{cmH}_{2} \mathrm{O}$ (\% pred) & $29.5 \pm 6.69(21.4 \pm 5.3)$ & $165.58 \pm 11.34(116.3 \pm 7.4)$ & $<10^{-9}$ & $<10^{-9}$ \\
\hline PEF L.s ${ }^{-1}(\%$ pred $)$ & $2.67 \pm 0.38(32.9 \pm 4.2)$ & $10.20 \pm 0.56(113.0 \pm 5.6)$ & $<10^{-6}$ & \\
\hline PCF L.S $\mathrm{S}^{-1}$ & $2.49 \pm 0.39$ & $10.07 \pm 0.50$ & $<10^{-8}$ & \\
\hline$V_{T} \mathrm{~L}$ & $0.41 \pm 0.03$ & $0.96 \pm 0.06$ & $<10^{-7}$ & \\
\hline$f_{\mathrm{R}}$ bpm & $27 \pm 2$ & $14 \pm 1.7$ & $<10^{-4}$ & \\
\hline$V^{\prime} E$ L.min $\min ^{-1}$ & $10.6 \pm 0.6$ & $12.6 \pm 1.3$ & 0.19 & \\
\hline Heart rate beats $\cdot \min ^{-1}$ & $83 \pm 6$ & $73 \pm 5$ & 0.34 & \\
\hline $\mathrm{Pa} \mathrm{mmHg}$ & $87 \pm 6$ & $80 \pm 4$ & 0.36 & \\
\hline
\end{tabular}

Data are presented as mean \pm SEM (\% predicted), unless otherwise stated. RMW: respiratory muscle weakness; FVC: forced vital capacity; FEV1: forced expiratory volume in $1 \mathrm{~s}$; TLC: total lung capacity; VC: vital capacity; IC: inspiratory capacity; FRC: functional residual capacity; ERV: expiratory reserve volume; RV: residual volume; MIP: maximum inspiratory pressure; MEP: maximum expiratory pressure; PEF: peak expiratory flow; PCF: peak cough flow; $V T$ : tidal volume; $f R$ : respiratory frequency; $V^{\prime} E$ : minute ventilation; $P$ a: mean arterial pressure. ${ }^{\#}$ : $p$-values for comparisons of absolute measures of subject characteristics in the RMW group versus controls. ": p-values for comparisons of \% pred measures of lung function parameters in the RMW group versus controls.

\section{Expiratory flow}

At baseline, unassisted PEF and PCF were both lower in the RMW group relative to controls (both $\mathrm{p}<0.001$ ) (table 1). LVR had no significant effect on unassisted PEF and PCF in either group at any time point following LVR (all p>0.05) (table 2). However, PEFLVR was significantly higher than unassisted PEF at baseline in the RMW group $(\mathrm{p}<0.05)$, but not in controls $(\mathrm{p}=0.33)$ (figure 2$)$.

\section{Cardiovascular responses}

During the plateau phase of the inflations, mean $P_{a}$ decreased significantly by $10.4 \pm 2.8 \mathrm{mmHg}$ and $17.3 \pm 3.0 \mathrm{mmHg}$ relative to baseline in the RMW and controls groups, respectively (both $\mathrm{p}<0.05)$. The decrease in mean $P$ a was significantly greater in the control group than in the RMW group $(p<0.05)$ (figure 3$)$. During the expiration following each LVR manoeuvre, mean $P$ a returned to baseline in the RMW group ( $\mathrm{p}=0.25)$, but

\section{TABLE 2 Lung volume recruitment data}

\begin{tabular}{lccc} 
& RMW & Controls & p-value $^{\#}$ \\
\hline PEFLVR L-s & & \\
MIC L & $3.72 \pm 0.24$ & $9.55 \pm 0.63$ & $<10^{-4}$ \\
MIC-VC difference L & $2.04 \pm 0.35$ & $5.33 \pm 0.21$ & $<10^{-6}$ \\
$P_{\text {mo }} \mathbf{~ c m H ~}_{\mathbf{2}} \mathbf{O}$ & $0.97 \pm 0.21$ & $0.08 \pm 0.22$ & 0.002 \\
Inflation time & $31.9 \pm 2.48$ & $38.9 \pm 1.68$ & 0.03 \\
Plateau time $^{+} \mathbf{s}$ & $2.56 \pm 0.28$ & $2.25 \pm 0.29$ & 0.45 \\
& $6.42 \pm 0.60$ & $7.18 \pm 0.55$ & 0.37
\end{tabular}

Data are presented as mean \pm SEM, unless otherwise stated. RMW: respiratory muscle weakness; PEFLVR: peak expiratory flow during lung volume recruitment; MIC: maximal insufflation capacity; VC: vital capacity; Pmo: mouth pressure. \#: p-values for comparisons between the RMW group versus controls; ": time required to reach maximal $P_{\text {mo }}$ during lung volume recruitment; ${ }^{+}$: time maximal $P_{\text {mo }}$ was held during lung volume recruitment. 

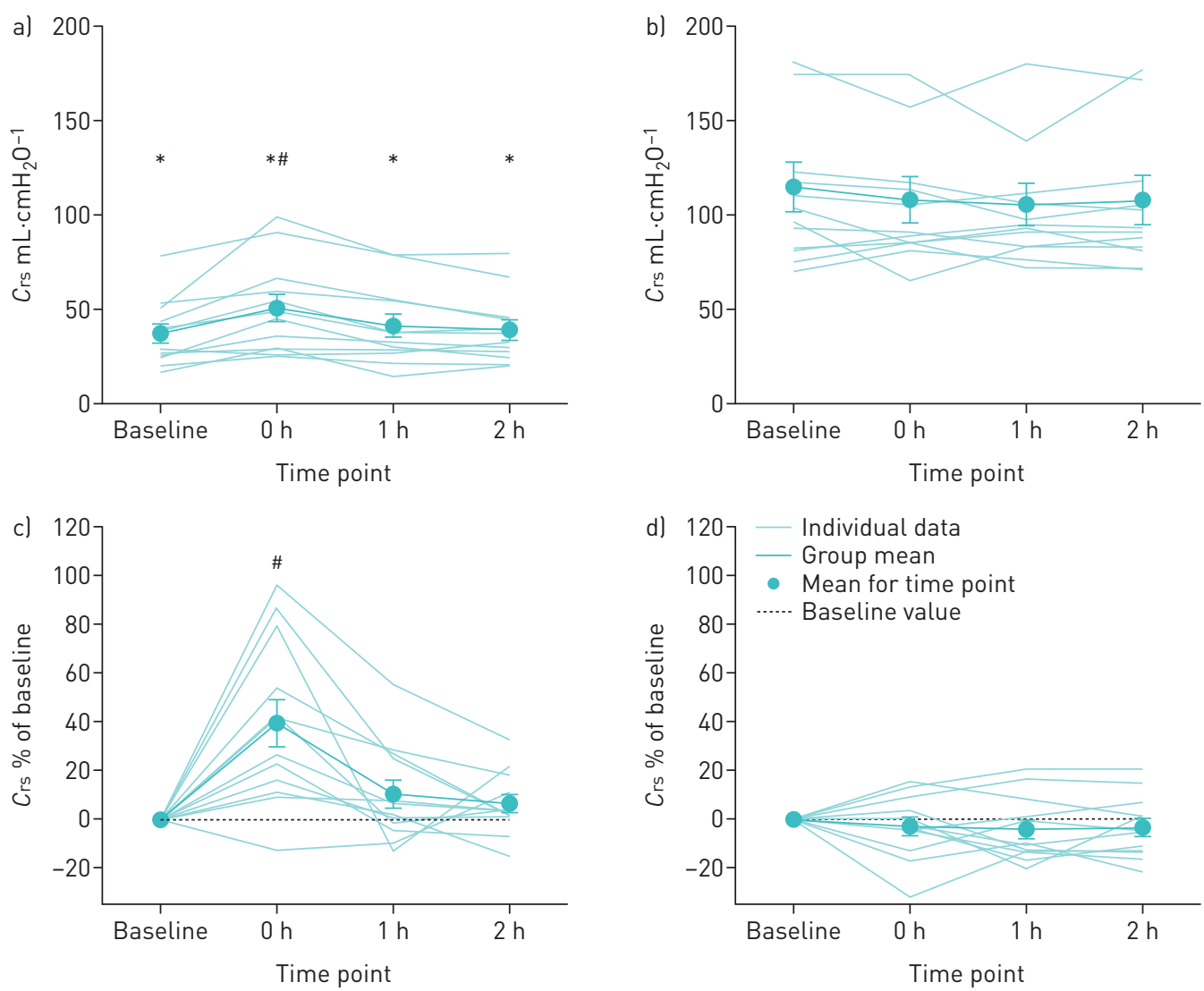

FIGURE 1 Compliance of the respiratory system $\left(C_{r s}\right)$ at baseline and $0 \mathrm{~h}, 1 \mathrm{~h}$ and $2 \mathrm{~h}$ following lung volume recruitment. a) Absolute $C_{\text {rs }}$ in the respiratory muscle weakness (RMW) group (see also table 3); b) absolute $C_{\text {rs }}$ in the control group (see also table 3); c) changes in $C_{\text {rs }}$ expressed as a function of baseline in the RMW group; d) changes in Crs expressed as a function of baseline in the control group. All data are presented as mean \pm SEM. *: $p<0.05$ for RMW versus control subjects; ${ }^{*}: p<0.05$ relative to baseline.

increased relative to baseline in the controls $(\mathrm{p}<0.05)$. In the control group, heart rate was significantly increased relative to baseline during the plateau phase of the each LVR manoeuvre $(p<0.05)$, but returned to baseline during the expiration phase $(p=0.29)$. No significant changes in heart rate were observed during LVR in the RMW group $(\mathrm{p}=0.40)$.
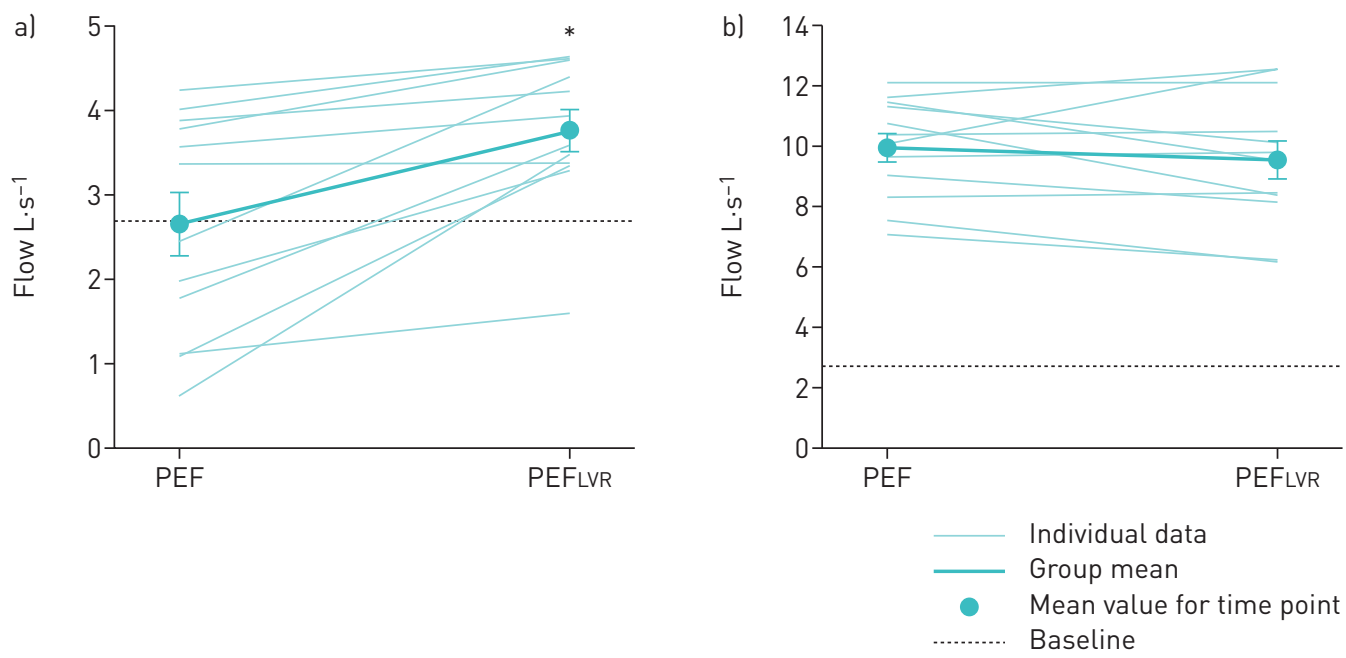

FIGURE 2 Peak expiratory flow (PEF) at baseline and PEF during lung volume recruitment (PEFLVR) in the a) respiratory muscle weakness and b) control groups. Data are presented as mean \pm SEM. *: significantly greater than PEF $(p<0.05)$. 


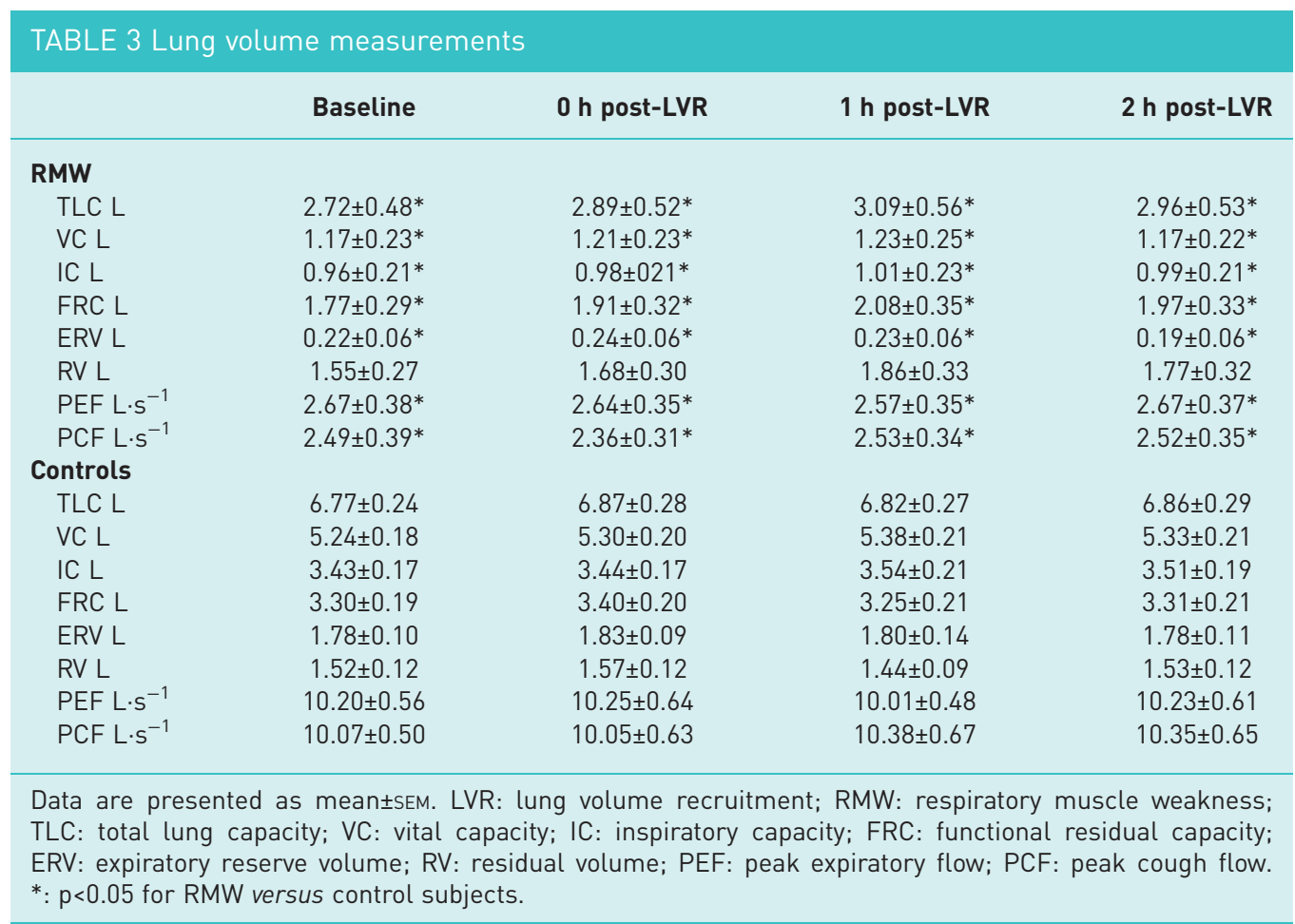

\section{Discussion}

There are four main findings from the present study. First, LVR delivered to the maximum tolerated pressure (or $50 \mathrm{cmH}_{2} \mathrm{O}$ ) with a prolonged breath-hold acutely increased Crs in individuals with severe RMW. Second, the acute increase in Crs was short-lived, with Crs returning to baseline within $1 \mathrm{~h}$ following the intervention. Third, during LVR, PEFLVR was increased due to passive increases in lung volume, but did not affect unassisted PCF and PEF thereafter. Fourth, the high inspiratory pressures associated with LVR reduced mean $P$ a during lung inflations. Collectively, our findings demonstrate the presence of an acute physiological benefit from LVR, but also indicate caution in those prone to hypotension.

\section{Respiratory system compliance}

It has been suggested that LVR may attenuate the decline in VC in disorders such as Duchenne muscular dystrophy by improving $C_{r s}[15,16]$. We found that one session of LVR acutely increases Crs by $39.5 \pm 9.8 \%$ above baseline in individuals with RMW; however, the improvement was transient as Crs returned to baseline within $1 \mathrm{~h}$ (figure 1). Approaches similar to LVR, such as intermittent positive pressure ventilation (IPPV) have previously been used in an attempt to acutely increase compliance in individuals with RWM. No effect was demonstrated with IPPV on Crs, lung compliance and chest-wall compliance in a patient population similar to that in the present study $[21,22]$. Conversely, others have reported that IPPV increases $C_{r s}$ in patients with kyphoscoliosis [31], and increases lung compliance in patients with amyotrophic lateral sclerosis [17]. Several factors may explain the conflicting results. First, IPPV and LVR are similar in that they passively increase lung volume, but important differences must be considered. Unlike LVR, IPPV does not involve an inspiratory breath-hold, but rather increases inspiratory pressure over the course of a standard duty cycle. Breath-holds during manual hyperinflation for ventilated patients in the intensive care unit have been shown to increase Crs [32]. In the current study, the breath-hold at peak inflation pressure lasted $6.42 \pm 0.60 \mathrm{~s}$ for individuals with RMW. Second, inflation pressures are variable within and between studies, in the range $18-40 \mathrm{cmH}_{2} \mathrm{O}[17,21,22,31]$. In the current study, the average inflation pressure delivered to those with $\mathrm{RMW}$ was $31.9 \pm 2.48 \mathrm{cmH}_{2} \mathrm{O}$, which is higher than pressures used in previous studies [17, 21, 22, 31]. It is possible that acute increases in Crs are only evident above a critical inflation pressure threshold. Lastly, in most cases the inflation volume delivered in previous studies has either been roughly equal to $\mathrm{VC}[21]$ or was not measured [17, 22, 31]. In the current study, the volume delivered was $192 \pm 27 \%$ of $\mathrm{VC}$, thus ensuring that the structures of the respiratory system were stretched beyond their chronically limited range of motion. Thus, the LVR stimulus delivered in the current study was of sufficient magnitude to produce an acute increase in Crs. 
At baseline, individuals in the RMW group had lower Crs than controls. Four mechanisms could explain the low $C$ rs in individuals with RMW: atelectasis [1,3], stiffening of the lung tissue [33], ankylosis of the costosternal and costovertebral joints [8] and increasing alveolar surface forces [34, 35]. Presumably, LVR serves to temporarily mitigate the influence of one or several of the aforementioned factors. Given that no changes in lung volumes were observed following LVR (table 3), we can surmise that LVR did not resolve atelectasis (if present). It is possible that LVR causes intrinsic changes to the mechanical properties of the tissues of the lung or the chest wall. Inflations achieving large increases in lung volume may act as a range of motion exercise for the articulations of the chest wall, thereby improving their laxity. This effect may be lost over time as restricted respiratory movements resume post-inflation. Acute changes in lung compliance may also be achieved through a redistribution of alveolar surface forces without a change in static lung volumes. Indeed, deep breathing alone has been shown to acutely increase lung compliance [2,34-36], and recruitment manoeuvres have been shown to enhance the effect of administered surfactant [37]. Repeated inflations above voluntary VC may produce a similar response. The absence of differences in Crs following LVR in controls is probably related to the fact that they are capable of intermittently increasing lung volume voluntarily [36]. While our data support the notion of LVR having a positive effect on Crs, further research is required to determine whether the observed change in $C$ rs was attributable to improvements in lung and/or chest wall compliance, and whether regular use of LVR elicits prolonged improvements in respiratory mechanics.

\section{Peak expiratory and peak cough flows}

For patients with RMW, the ability to clear airway secretions by coughing is essential to avoid respiratory tract infections and minimise respiratory complications [12]. A PCF $\geqslant 2.7 \mathrm{~L} \cdot \mathrm{s}^{-1}$ (or $\geqslant 160 \mathrm{~L} \cdot \mathrm{min}^{-1}$ ) is considered to be the threshold for effective airway clearance after a successful extubation [38]. Half the subjects in the RMW group had an unassisted PCF and PEF $<2.7 \mathrm{~L} \cdot \mathrm{s}^{-1}$ at baseline, and LVR had no effect on unassisted PCF or PEF (table 3). In contrast, CLEARY et al. [20] showed that LVR acutely increased unassisted PCF from 4.19 to $5.08 \mathrm{~L} \cdot \mathrm{s}^{-1}$ in a group of patients with amyotrophic lateral sclerosis, and they concluded that the increase in unassisted PCF was related to increases in VC via an increase in Crs. However, in our population with relatively
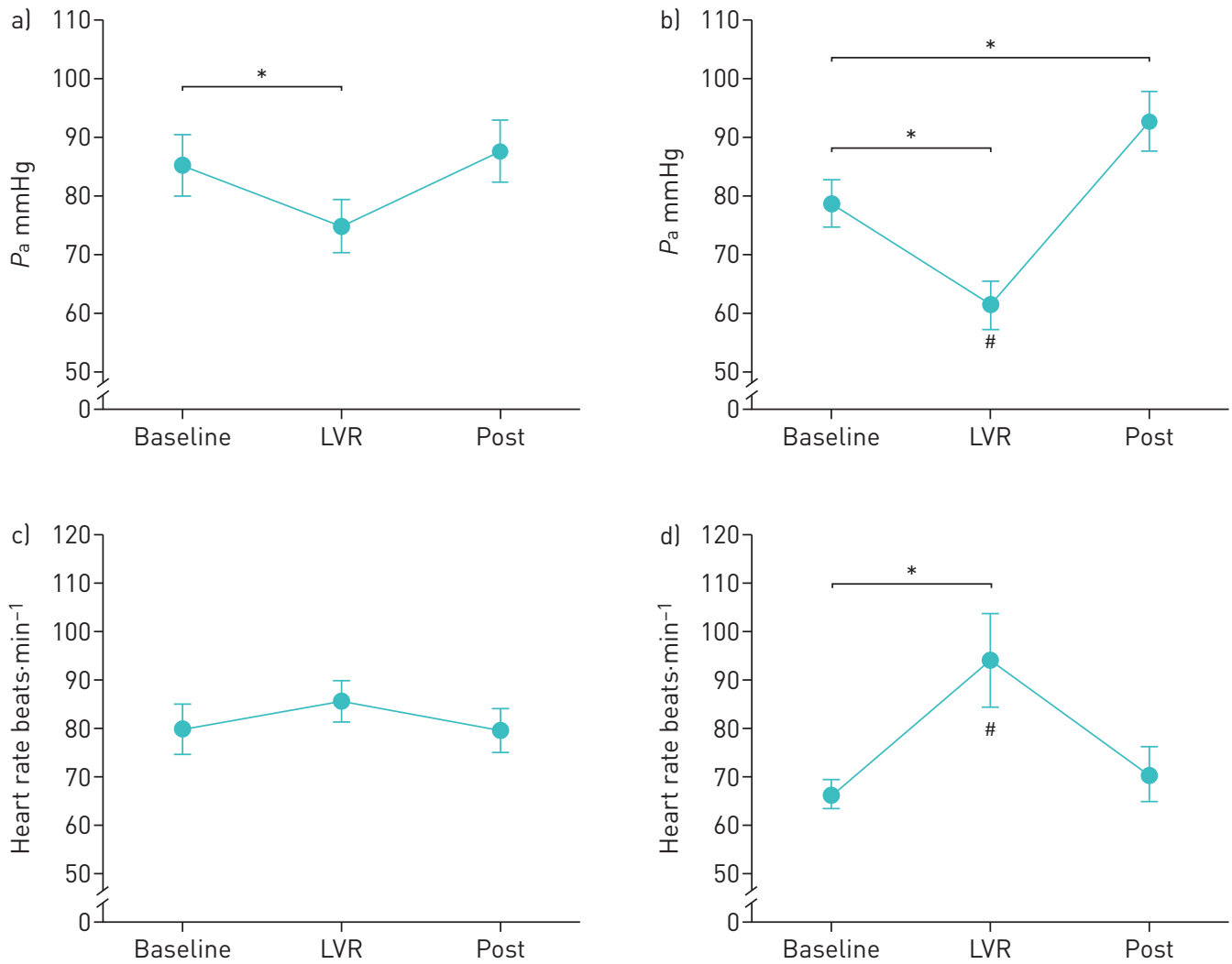

FIGURE 3 Average mean arterial pressure $(P a)$ during lung volume recruitment (LVR) in (a) the respiratory muscle weakness (RMW) group and (b) the control group. Average heart rate during LVR in (c) the RMW group and (d) the control group. Data for each time point are presented as mean \pm SEM. Baseline: $5 \mathrm{~s}$ prior to each LVR manoeuvre; LVR: the entire plateau phase of inflation; post: during the $5 \mathrm{~s}$ following each LVR manoeuvre. *: $p<0.05$ for RMW versus control subjects. ${ }^{\#}$ : $p<0.05$ relative to baseline. 

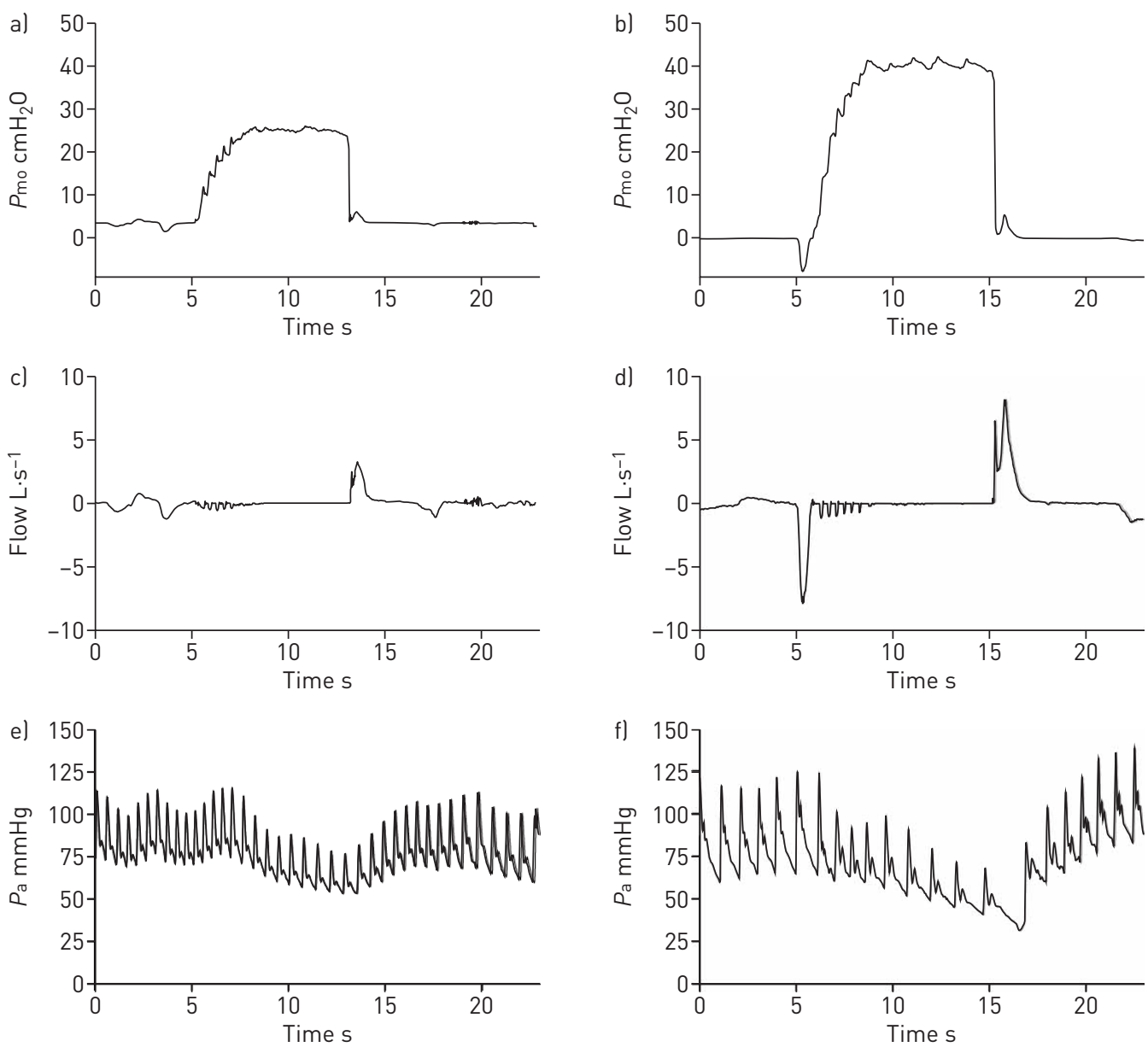

FIGURE 4 Mouth pressure $\left(P_{\mathrm{mo}}\right)$, flow rate and mean arterial blood pressure $\left(P_{\mathrm{a}}\right)$ data during a single lung volume recruitment manoeuvre in representative subjects in the respiratory muscle weakness (RMW) group in (a), (c), and (e), and in the control group in (b), (d), and (f). Data are presented for a subject in the RMW group with Duchenne muscular dystrophy and a healthy age- and sex-matched subject in the control group. All data presented are raw traces.

greater degree of ventilatory impairment, VC was unaffected by LVR. Despite transiently increased Crs, those in the RMW group were unable to voluntarily achieve higher lung volumes following LVR. However, during the LVR protocol, the MICs achieved were $192 \pm 27 \%$ of VC in the RMW group. Accordingly, PEFLVR was significantly greater than unassisted PCF and PEF at any time point by virtue of the increased elastic recoil at higher lung volumes. More importantly, the average PEFLVR value was above the $2.7 \mathrm{~L} \cdot \mathrm{s}^{-1}$ threshold by $1.1 \pm 0.28 \mathrm{~L} \cdot \mathrm{s}^{-1}$ (figure 2), supporting the notion that when coupled with a forced expiration, LVR can increase expiratory flow and thus could improve airway clearance $[15,39]$.

\section{Cardiovascular responses}

While LVR improved $C_{r}$ and expired flow, the elevated pressures delivered during inflation had concomitant cardiovascular effects. During LVR manoeuvres, mean $P$ a decreased relative to baseline in both groups (figures 3 and 4), probably due to increases in intrathoracic pressure and reduced venous return [40]. The decrease in mean $P$ a was greater in the controls than in those with RMW (figure 3), presumably due to the fact that controls tolerated higher inflation pressures (table 2). Furthermore, in the controls, the fall in mean $P$ a was paralleled by an increase in heart rate, presumably to maintain cardiac output (figure $3 \mathrm{~b}$ ). However, this response was absent in the RMW group, since 10 out of 12 individuals were taking $\beta$-blockers, which would have attenuated the increase in heart rate (figure $3 \mathrm{a}$ ). Once the inflation pressure was relieved, mean $P$ a returned to baseline in the RMW group, but increased significantly above baseline in the controls $(\mathrm{p}<0.05)$ (figure 3 ). While the inflations were generally well tolerated, three out of 12 individuals in the RMW group and five out of 12 controls reported symptoms of hypotension such as lightheadedness. If the effects of LVR are predominantly mediated through consistent, regular performance above a critical inflation pressure, the potential to produce hypotension could represent a significant barrier in achieving longer term adherence to LVR. 


\section{Limitations}

While the current study reveals novel findings relating to the physiological effects and clinical importance of LVR, some limitations must be considered. First, the observed increase in Crs could be related to improvements in the compliance of the lung, the chest wall, or both. However, our data do not permit the dissociation of the respective components of Crs. Second, it is unclear how long the positive effects of LVR on Crs last within the hour following LVR. Third, only one female subject was included in each study group and we cannot comment on any potential sex difference. Lastly, the pulse method of measuring Crs has two inherent limitations: $C r$ is measured on the inspired limb of the pressure volume curve, and the measures of $C$ rs are neither dynamic nor static. Thus, direct comparison of pulse method derived measures of $C$ rs to other studies is difficult.

\section{Conclusion}

For individuals with severe RMW, a single session of LVR delivered to maximal tolerance and with a breath-hold acutely increases Crs. Furthermore, LVR augments PEF during the manoeuvres, but does not acutely affect unassisted PEF or PCF. Despite these findings, blood pressure changes observed during LVR may be of clinical importance to those with cardiovascular comorbidities or who are prone to hypotension, and any associated symptoms could limit adherence to LVR. Collectively, these findings provide an important physiological basis for the use of LVR in severe RMW.

\section{Acknowledgements}

Y. Molgat-Seon, L.M. Hannan, D.A. McKim, A.W. Sheel and J.D. Road designed the study. Y. Molgat-Seon, L.M. Hannan, P.B. Dominelli, C.M. Peters and R.J. Fougere enrolled subjects and conducted data collection. Y. Molgat-Seon, L.M. Hannan, P.B. Dominelli and C.M. Peters analysed the data. All authors had complete access to all of the study data and contributed to drafting and critically revising the manuscript. All authors approved the final version of the manuscript and take responsibility for the integrity of the data and the accuracy of the data analysis.

\section{References}

1 De Troyer A, Borenstein S, Cordier R. Analysis of lung volume restriction in patients with respiratory muscle weakness. Thorax 1980; 35: 603-610.

2 Estenne M, Gevenois PA, Kinnear W, et al. Lung volume restriction in patients with chronic respiratory muscle weakness: the role of microatelectasis. Thorax 1993; 48: 698-701.

3 Gibson GJ, Pride NB, Davis JN, et al. Pulmonary mechanics in patients with respiratory muscle weakness. Am Rev Respir Dis 1977; 115: 389-395.

4 Almenoff PL, Spungen AM, Lesser M, et al. Pulmonary function survey in spinal cord injury: influences of smoking and level and completeness of injury. Lung 1995; 173: 297-306.

5 Rideau Y, Jankowski LW, Grellet J. Respiratory function in the muscular dystrophies. Muscle Nerve 1981; 4: $155-164$

6 Stone DJ, Keltz $\mathrm{H}$. The effect of respiratory muscle dysfunction on pulmonary function. studies in patients with spinal cord injuries. Am Rev Respir Dis 1963; 88: 621-629.

7 Estenne M, De Troyer A. The effects of tetraplegia on chest wall statics. Am Rev Respir Dis 1986; 134: 121-124.

8 Estenne M, Heilporn A, Delhez L, et al. Chest wall stiffness in patients with chronic respiratory muscle weakness. Am Rev Respir Dis 1983; 128: 1002-1007.

9 Wang AY, Jaeger RJ, Yarkony GM, et al. Cough in spinal cord injured patients: the relationship between motor level and peak expiratory flow. Spinal Cord 1997; 35: 299-302.

10 Suárez AA, Pessolano FA, Monteiro SG, et al. Peak flow and peak cough flow in the evaluation of expiratory muscle weakness and bulbar impairment in patients with neuromuscular disease. Am J Phys Med Rehabil 2002; 81: 506-511.

11 Reines HD, Harris RC. Pulmonary complications of acute spinal cord injuries. Neurosurgery 1987; 21: 193-196.

12 Tzeng AC, Bach JR. Prevention of pulmonary morbidity for patients with neuromuscular disease. Chest 2000; 118: 1390-1396.

13 Silver JR, Gibbon NO. Prognosis in tetraplegia. BMJ 1968; 4: 79-83.

14 Simonds AK. Respiratory complications of the muscular dystrophies. Semin Respir Crit Care Med 2002; 23 : 231-238.

15 McKim DA, Katz SL, Barrowman N, et al. Lung volume recruitment slows pulmonary function decline in Duchenne muscular dystrophy. Arch Phys Med Rehabil 2012; 93: 1117-1122.

16 Katz SL, Barrowman N, Monsour A, et al. Long-term effects of lung volume recruitment on maximal inspiratory capacity and vital capacity in Duchenne muscular dystrophy. Ann Am Thorac Soc 2016; 13: 217-222.

17 Lechtzin N, Shade D, Clawson L, et al. Supramaximal inflation improves lung compliance in subjects with amyotrophic lateral sclerosis. Chest 2006; 129: 1322-1329.

18 Hyatt RE, Schilder DP, Fry DL. Relationship between maximum expiratory flow and degree of lung inflation. J Appl Physiol 1958; 13: 331-336.

19 Kang SW, Bach JR. Maximum insufflation capacity. Chest 2000; 118: 61-65.

20 Cleary S, Misiaszek JE, Kalra S, et al. The effects of lung volume recruitment on coughing and pulmonary function in patients with ALS. Amyotroph Lateral Scler Frontotemporal Degener 2013; 14: 111-115.

21 McCool FD, Mayewski RF, Shayne DS, et al. Intermittent positive pressure breathing in patients with respiratory muscle weakness. Alterations in total respiratory system compliance. Chest 1986; 90: 546-552.

22 De Troyer A, Deisser P. The effects of intermittent positive pressure breathing on patients with respiratory muscle weakness. Am Rev Respir Dis 1981; 124: 132-137. 
23 American Thoracic Society/European Respiratory Society. ATS/ERS statement on respiratory muscle testing. Am J Respir Crit Care Med 2002; 166: 518-624.

24 Miller MR, Hankinson J, Brusasco V, et al. Standardisation of spirometry. Eur Respir J 2005; 26: 319-338.

25 Wanger J, Clausen JL, Coates A, et al. Standardisation of the measurement of lung volumes. Eur Respir J 2005; 26 : 511-522.

26 Wilson SH, Cooke NT, Edwards RH, et al. Predicted normal values for maximal respiratory pressures in caucasian adults and children. Thorax 1984; 39: 535-538.

27 Crapo RO, Morris AH, Clayton PD, et al. Lung volumes in healthy nonsmoking adults. Bull Eur Physiopathol Respir 1982; 18: 419-425.

28 Crapo RO, Morris AH, Gardner RM. Reference spirometric values using techniques and equipment that meet ATS recommendations. Am Rev Respir Dis 1981; 123: 659-664.

29 Suratt PM, Owens DH, Kilgore WT, et al. A pulse method of measuring respiratory system compliance. J Appl Physiol Respir Environ Exerc Physiol 1980; 49: 1116-1121.

30 Borg GA. Psychophysical bases of perceived exertion. Med Sci Sports Exerc 1982; 14: 377-381.

31 Sinha R, Bergofsky EH. Prolonged alteration of lung mechanics in kyphoscoliosis by positive pressure hyperinflation. Am Rev Respir Dis 1972; 106: 47-57.

32 Hodgson C, Denehy L, Ntoumenopoulos G, et al. An investigation of the early effects of manual lung hyperinflation in critically ill patients. Anaesth Intensive Care 2000; 28: 255-261.

33 Lessa TB, de Abreu DK, Rodrigues MN, et al. Morphological and ultrastructural evaluation of the golden retriever muscular dystrophy trachea, lungs, and diaphragm muscle. Microsc Res Tech 2014; 77: 857-861.

34 Young SL, Tierney DF, Clements JA. Mechanism of compliance change in excised rat lungs at low transpulmonary pressure. J Appl Physiol 1970; 29: 780-785.

35 Ferris BG, Pollard DS. Effect of deep and quiet breathing on pulmonary compliance in man. J Clin Invest 1960; 39: $143-149$.

36 Suratt PM, Owens DH, Hsiao H, et al. Lung compliance and its transient elevations measured with pulse-flow method. J Appl Physiol Respir Environ Exerc Physiol 1981; 50: 1318-1324.

37 Krause $\mathrm{M}$, Olsson $\mathrm{T}$, Law $\mathrm{AB}$, et al. Effect of volume recruitment on response to surfactant treatment in rabbits with lung injury. Am J Respir Crit Care Med 1997; 156: 862-866.

38 Bach JR, Saporito LR. Criteria for extubation and tracheostomy tube removal for patients with ventilatory failure. A different approach to weaning. Chest 1996; 110: 1566-1571.

39 McKim DA, Road J, Avendano M, et al. Home mechanical ventilation: a Canadian Thoracic Society clinical practice guideline. Can Respir J 2011; 18: 197-215.

40 Luce JM. The cardiovascular effects of mechanical ventilation and positive end-expiratory pressure. JAMA 1984; 252: $807-811$. 